\title{
CHESTNUT COVER AUTOMATIC CLASSIFICATION THROUGH LIDAR AND SENTINEL-2 MULTI-TEMPORAL DATA
}

\author{
L. Alonso ${ }^{1}$, J. Armesto ${ }^{1 *}$, J. Picos ${ }^{1}$ \\ ${ }^{1}$ Forestry Engineering School, University of Vigo, A Xunqueira campus, Pontevedra, 36005, Spain -(laura.alonso.martinez, julia, \\ jpicos)@uvigo.es
}

Commission III, WG III/10

KEY WORDS: Sentinel 2, multi-temporal analysis, chestnut cover, LiDAR, forest, remote sensing

\begin{abstract}
:
Chestnut (Castanea sativa Mill.) managed forests in Galicia (Northwestern Spain) have important cultural, economic and ecosystem values. However, due to rural exodus chestnut stands are being degraded. In order to take restoration and conservation measures knowledge of these forests' location, expanse and stage is needed. The available Spanish official cartography is based on photointerpretation which is inaccurate in terms of chestnut forest location and classification. However, remote sensing has recently been proven to be an effective tool for this purpose. Sentinel 2 multi-temporal classification is recently acquiring importance as a method to classify tree species. This project intends to detect chestnut forests using LiDAR and Sentinel 2 multi-temporal data and to compare these results with those obtained using the official cartography. It also intends to assess how the use of different phenological stages could improve classification results. The results obtained provide an overall accuracy of $76 \%$ when a threemonth combination is used: (March, July and September) leaf-off stage, flowering and leaf-on stage. Overlapping of the current map and the official cartography lead to an accuracy and precision increase; highlighting the utility of the presented methodology to acquire knowledge about chestnut forests location.
\end{abstract}

\section{INTRODUCTION}

Information about forest resource distribution remains essential for policy makers and land management. European chestnut (Castanea sativa Mill.) covers more than 2.5 million ha in Europe of which $98.3 \%$ are managed forests used for wood or fruit production purposes (Conedera et al., 2004). Since the first half of the last century, a decreased importance of this species as a staple food and a progressive depopulation of rural areas has caused the abandonment of chestnut agriculture (Zlatanov et al., 2013), an abandonment which has been accelerated due to pathogens (Baser and Bozoglu, 2020) and invasive species (Battisti et al., 2014). However, in recent decades chestnut tree management has once again become viable and shows great potential as a source of income thanks to research in biological control and genetics (Acquadro et al., 2019; Trapiello et al., 2017). Galician chestnut forests (Northwestern Spain) have been managed for chestnut production for centuries (Fernández et al., 1998). The result is forests with important ecological, ecosystem and cultural values. In recent years, rural abandonment has led to stand degradation and to a loss of knowledge of their distribution. However these stands still have the potential to become an important source of income for rural areas and to keep providing ecosystem, recreational and cultural services (Roces-Díaz et al., 2018). In order to recover the ecosystem, knowledge of its current expanse and stage is needed. The current official source of forest location, distribution, expanse and classification in Spain is the Spanish Forest Map (MFE). The Spanish cartographic official source (MFE) is elaborated through photointerpretation and field work on a 1:25000 scale (Miteco, 2014). It consists of a set of polygons where the type of forest, along with its principal and secondary species composition are indicated. Chestnut forest pure stands are classified as a "castañar" type of forest. However, when mapping chestnut forest stands, the method and resolution used can become a problem leading to surface overestimation or underestimation. This compromises decision making when it comes to chestnut production or conservation measures.

Nowadays, tree species distribution can be acquired using remote sensing techniques. Medium spatial resolution satellites (especially Landsat 8 and Sentinel 2) are the most cost-efficient tool and the current trend in tree-species-classification-related studies (Fassnacht et al., 2016). Of the open-data satellites, Sentinel 2 is the one which obtains images with the highest spatial resolution $(10 \mathrm{~m}$ to $20 \mathrm{~m})$ and the highest spectral resolution (up to 13 bands). Three of the 13 bands are red edge bands, which are not available from satellites like Landsat, and have been shown to be important in tree species classification (Immitzer et al., 2016). The free availability and the high revisit time (5 days) of these satellites, which allow for the acquisition of multiple images corresponding to different vegetation stages at the same area, has recently led to the incorporation of multitemporal analysis to vegetation classification related studies (Fassnacht et al., 2016). These analyses are especially suitable for boreal and temperate climates where changes in plant phenology throughout the year can help to discriminate between different species.

In addition to satellite images, LiDAR sensors play an important role in land cover classification as well. Thanks to

* Corresponding author 
their ability to estimate vegetation height they are a tool that efficiently discriminates classes with spectral similitudes (Sothe et al., 2018). Recently available LiDAR data on National Geographic databases have led to the incorporation of this technology in vegetation studies (Barrett et al., 2016).

This study aims to classify areas covered by chestnut forests and to analyze the potential of using multi-temporal information for this purpose. It also intends to provide a tool which can be used to improve the accuracy of the official cartography based on open-access data. Therefore, comparisons between the official maps and the results obtained from this study will be performed.

\section{MAIN BODY}

The study area is in Galicia (Northwestern Spain). Although knowledge of chestnut location and expanse is relevant in the whole Galician region, a small study area was selected to develop the method and study its potential. The selected area was the municipality of Folgoso do Courel, due to its abundance of chestnut managed forests. The municipality covers an area of $193 \mathrm{~km}^{2}$ and is a mountainous area with small, steep valleys with different aspects. (See Figure 1)

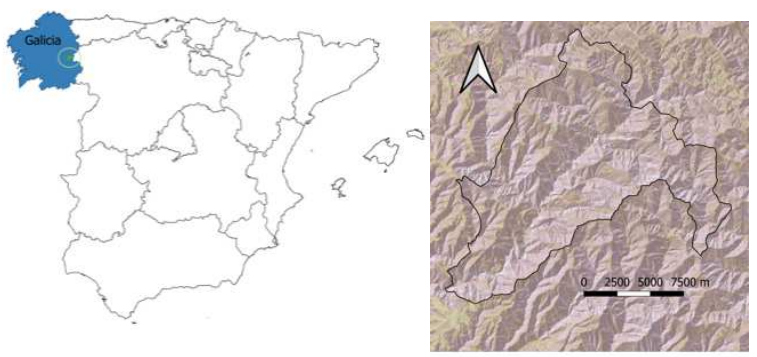

Figure 1. Study area. Background image hillshade and slope obtained from the Spanish Cartographical Institute (IGN, 2019).

The area is covered fundamentally by temperate mixed forest including 237 different species of dicotyleoneous plants (Quercus pyrenaica, Betula alba, Quercus suber, Quercus robur, Fagus sylvatica, Alnus glutinosa, Corylus avellana, Ilex acquifolium, Juglans regia, Prunus avium, Salix sp., Fraxinus sp.,...).The region's climate has a mediterranean influence, therefore species such as Quercus ilex can be found as well. However, Castanea sativa pure stands, due to management, cover an important part of the area. There are plantations of coniferous trees as well, mainly of: Pinus pinaster, Pinus radiata and Pinus sylvestris. (Xunta de Galicia/USC, 2005.)

Chestnut phenology in the study area is not homogeneous due to differences in height and aspect. These variations are increased due to the presence of different chestnut cultivars (Pereira-Lorenzo et al., 2001). However, as a general guideline senescence occurs in November (assessed through field work), sprouting from mid to late May according to local forest technicians and blooming from mid-June to late July (Fernández-López et al., 2013).

\subsection{Data acquisition and analysis}

Sentinel 2 is one of the ESA's (European Space Agency) satellites constellations equipped with a multispectral camera. It samples 13 spectral bands, which range from a $10 \mathrm{~m}$ to a $60 \mathrm{~m}$ spatial resolution. The temporal resolution is up to 5 days. Table 1 shows the Spectral bands specifications. Sentinel 2 images were selected in order to perform the study. Images corresponding to the $2 \mathrm{~A}$ product were used (European Space Agency (ESA), 2015).

\begin{tabular}{|cccc|}
\hline Band & $\begin{array}{l}\text { Central } \\
\text { wavelength } \\
(\mathrm{nm})\end{array}$ & Bandwidth $(\mathrm{nm})$ & $\begin{array}{l}\text { Spatial } \\
\text { resolutio } \\
\mathrm{n}(\mathrm{m})\end{array}$ \\
\hline Band 1 & 443 & 20 & 60 \\
Band 2 & 490 & 65 & 10 \\
Band 3 & 560 & 35 & 10 \\
Band 4 & 665 & 30 & 10 \\
Band 5 & 705 & 15 & 20 \\
Band 6 & 740 & 15 & 20 \\
Band 7 & 783 & 20 & 20 \\
Band 8 & 842 & 115 & 10 \\
Band 8A & 865 & 20 & 20 \\
Band 9 & 945 & 20 & 60 \\
Band 10 & 1375 & 30 & 60 \\
Band 11 & 1610 & 90 & 20 \\
Band 12 & 2190 & 180 & 20 \\
\hline
\end{tabular}

Table 1. Specifications of Sentinel 2 bands provided by ESA (European Space Agency (ESA), 2015)

Images covering different phenological stages of the vegetation were used. Initially images from every season and every month were evaluated in order to optimize the multi-temporal analysis. However several months were finally discarded due to the presence of too much clouds, snow and shadows. The selected images for the analysis dated from March, May, July and September. The specific dates were: 26/03/2019, 05/05/2019, $19 / 07 / 2019$ and $12 / 09 / 2019$. Bands with $20 \mathrm{~m}$ and $10 \mathrm{~m}$ of spatial resolution were selected from all of the images obtained. Resampling on $10 \mathrm{~m}$ bands was performed in order to have a common resolution of $20 \mathrm{~m}$ across all bands.

LiDAR data were obtained from the Spanish Geographical Information System (IGN). Data is freely available. LiDAR point clouds were acquired in 2016 using an airborne laser scanner (ALS). The sensor was a LEICA ALS80 which allowed for a nominal point density of 0.5 points $/ \mathrm{m}^{2}$. Georeferecing was executed on the ETRS89 georeference system with a Root Mean Square Error (RMSE) of $0.3 \mathrm{~m}$ in the horizontal directions and $0.2 \mathrm{~m}$ in the vertical directions (Miteco, 2019).

\subsection{Methodology}

The present study methodology is based on an image classification process. However, as the study area has other land covers besides forest, a study area filtering step was performed using LiDAR data. Only areas with a height tall enough to be a forest were selected. The selected height threshold was $10 \mathrm{~m}$, based on analyses of the heights of chestnut areas. This step was performed using a calculated CHM (Canopy height model). To obtain the CHM, ground points were identified on the LiDAR point cloud and for the rest of the points the height above the ground was computed. This allowed for the generation of a normalized point cloud from which the CHM was created. CHM resolution was selected accordingly to match one of the Sentinel images $(20 \mathrm{~m})$. Pixels with a height value below $10 \mathrm{~m}$ were erased from the study area.

Different Sentinel 2 band combinations were created and visually analyzed to assess differences between seasons. Figure 2 shows the combination of bands $11 / 8 \mathrm{~A} / 4$ for the selected 
months where it is possible to see the variations in radiometry over the course of the seasons, especially between March-May and July-September. (a)

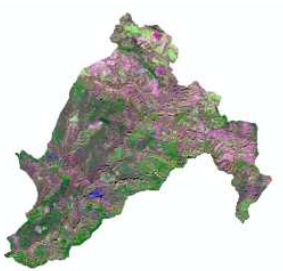

(c)

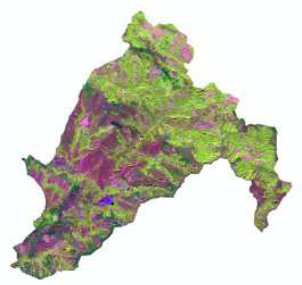

(b)

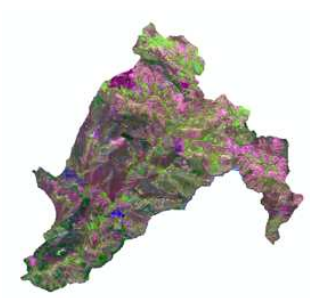

(d)

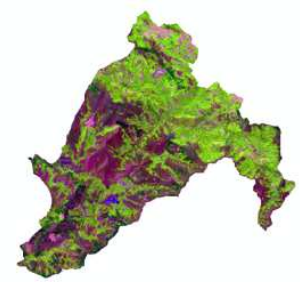

Figure 2. Sentinel band combination (11/8A/4) for images obtained in different months in the Municipality of Folgoso do Courel. (a) March (b) May (c) July (d) September

A multi-temporal classification approach was chosen as it has been shown that there is a potential for differences in radiometry due to phenology. The algorithm employed was Breiman's Random Forest (Breiman, 2001). The Random Forest is an algorithm that is extensively and successfully employed in other multi-temporal vegetation-classificationrelated studies such as (Hościło and Lewandowska, 2019) and (Persson et al., 2018a). To carry out the multi-temporal study several models based on the different month combinations were created. In order to acquire information about the relevance of including several months in the classification, four models were also created using just one month for contrast.

The Random forest algorithm was provided for training areas. There were two classes of training areas: chestnut and others. Others included the rest of forested areas present in the study area area such as other broadleaf forests and coniferous forests. Training areas were created through field work. Random transects were created on the road-accessible parts of the study area in order to look for pure stands that would be suitable training areas. Care was taken to ensure the transects covered different aspects, heights and slopes. Training area locations were marked with a GPS with centimeter accuracy (GEOMAX Zenith15). Finally, a set of 73 polygons were marked: 48 corresponding to other tree covers (Pine sp., Quercus ilex, Quercus pyrenaica, Betula alba, Alnus glutinosa,...) and 25 corresponding to chestnut forests (Castanea sativa). Bands combinations on different months were created to asses differences on radiometric answer between species and months. Figure 3 is an example of this step results. There it is possible to see band combination 11/8A/4 result on different forests for March image. Colorations result allow to see that there are differences between species radiometric behaviour.
Castanea sativa

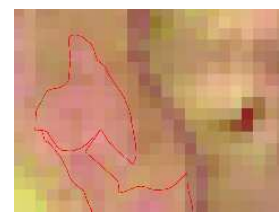

Mixed forest

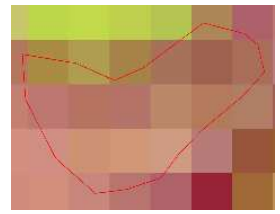

Quercus pyrenaica

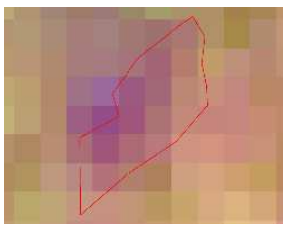

Quercus ilex

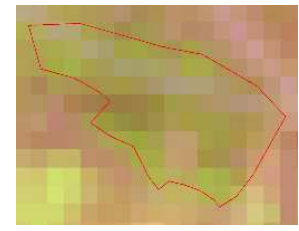

Pinus sp.

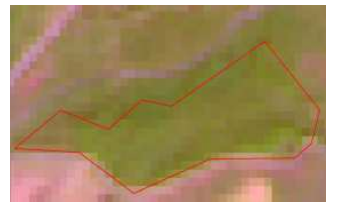

Figure 3. Sentinel 2 bands combination 11/8A/4 for March images.

Random forest models were applied to the whole study area. A cross-validation was performed in order to explore multitemporal results and to select the most efficient model. For this purpose, 100 random points were selected within the study area. Random points ground truth was obtained from photointerpretation of the PNOA image (PNOA, 2019).

Once the most accurate model was selected, results were crossreferenced with the official cartography of the study area in order to assess the differences.

\subsection{Results and discussion}

Cross-validation of the results acquired by random forest modelling reveals differences between the results obtained when using different months as predictive variables. These results are presented in Table 3. A higher overall accuracy (76\%) was obtained when using a combination of three months to create the model. The effectiveness of Sentinel 2 time series has been noted previously in multiple projects (Grabska et al., 2019; Hościło and Lewandowska, 2019; Persson et al., 2018). Previously mentioned studies classified forest stands according to all of the species present in an area using multi-temporal images and they obtained accuracies close to $85 \%$ when using the best month combinations. Accuracies obtained in this case study are lower (around 10\%). However, it was difficult to find pure stands of other broadleaves in order to have enough training areas. Future studies should focus on increasing field work efforts for this purpose.

Comparing cases where higher and lower Overall Accuracies were obtained, differences accounted for less than a $10 \%$. Larger differences exist in Users and Producers Accuracy. Several of the models do not allow an excess of $50 \%$ for these values, which could result in a random prediction of a class. Single month models for July and September periods are the least accurate. However, these months combined with March (Model 5) provide the best result. According to results, March 
and May are important months for the prediction of chestnut presence, revealing the importance of including images from senescence periods. Persson et al. (Persson et al., 2018) also note the importance of the leaf-off period, however they attribute it to images from early senesce which couldn't be included in this study due to cloud and shadow problems. They confirm that adding leaf-on periods helps to improve these results as well. However, in order to perform a better interpretation of the results it would be necessary to obtain phenology information about the rest of the broadleaves present in the study area.

\begin{tabular}{|l|l|l|l|l|l|l|}
\hline ID & Months & $\begin{array}{l}\text { OA } \\
(\%)\end{array}$ & $\begin{array}{l}\text { UA } \\
(\%) \\
\text { other }\end{array}$ & $\begin{array}{l}\text { UA } \\
(\%) \\
\text { cast }\end{array}$ & $\begin{array}{l}\text { PA } \\
(\%) \\
\text { other }\end{array}$ & $\begin{array}{l}\text { PA } \\
(\%) \\
\text { cast }\end{array}$ \\
\hline 1 & MA+MR+J+S & 75 & 79 & 60 & 87 & 53 \\
\hline 2 & MA+MR+J & 70 & 75 & 50 & 70 & 67 \\
\hline 3 & MA+MR+S & 74 & 79 & 58 & 86 & 46 \\
\hline 4 & MA+J+S & 76 & 78 & 65 & 90 & 43 \\
\hline 5 & MR+ J+S & 76 & 83 & 59 & 81 & 63 \\
\hline 6 & MA+MR & 74 & 78 & 59 & 87 & 43 \\
\hline 7 & MA+J & 71 & 76 & 52 & 85 & 50 \\
\hline 8 & MA+S & 72 & 76 & 55 & 88 & 67 \\
\hline 9 & MR+J & 74 & 83 & 55 & 78 & 63 \\
\hline 10 & MR+S & 73 & 84 & 54 & 75 & 67 \\
\hline 11 & J+S & 71 & 84 & 51 & 73 & 67 \\
\hline 12 & MA & 75 & 75 & 72 & 95 & 26 \\
\hline 13 & MR & 74 & 84 & 56 & 77 & 67 \\
\hline 14 & J & 68 & 82 & 47 & 70 & 63 \\
\hline 15 & S & 67 & 81 & 46 & 69 & 63 \\
\hline
\end{tabular}

Table 3. Random forest models performance. MR (March), MA (May), J (July), S (September), OA (Overall Accuracy), UA (Users Accuracy), PA (Producers Accuracy), cast (chestnut class), other (other class)

Model 5 revealed that chestnut cover in the Municipality of Folgoso do Courel amounts to 2,677 ha. Figure 4 shows the results obtained.

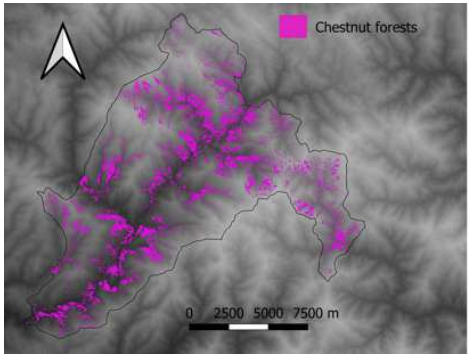

Figure 4. Chestnut mapping results obtained with Model 5. Background image: DTM (Digital Terrain Model) $5 \mathrm{~m}$ obtained from the Spanish Cartographical Institute (IGN, 2019).

The MFE chestnut area estimation greatly differs from the results presented in this study. The MFE polygons of chestnut pure stands cover an area of 3,208 ha. When overlapped, the MFE and Model 5 only match on $42 \%$ of the area (1,359 ha). The remaining 58\% (916 ha) are classified as other tree species. On the other hand, there are 402 ha of chestnut according to the MFE that are in fact not covered by forest. According to Model $5,1,318$ ha of chestnut forest are not currently classified by the official cartography. The results of these comparisons were evaluated through field work and photointerpretation. Figure 5 shows an example of an area that is not covered by trees that is included in the MFE chestnut polygons. Figure 6 shows an example of other tree covers that are included in the MFE chestnut polygons. Figure 7 shows an example of an area classified as a chestnut area by Model 5 but that is not included in the MFE chestnut polygons.

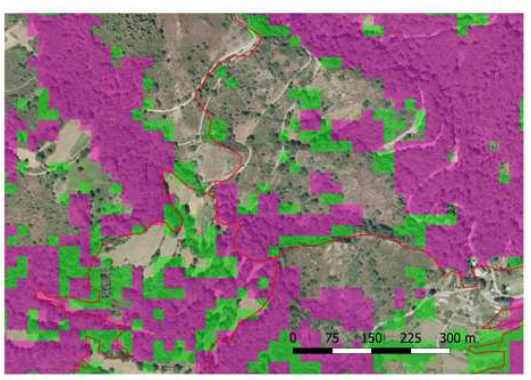

Figure 5. Model 5 classification results overlapped with the MFE. The figure shows how the MFE polygons cover nonforested areas. Red lines represent the MFE polygons. Pinkcolored areas are areas classified as chestnut while greencolored areas are classified as others. PNOA Reference image (PNOA, 2016)

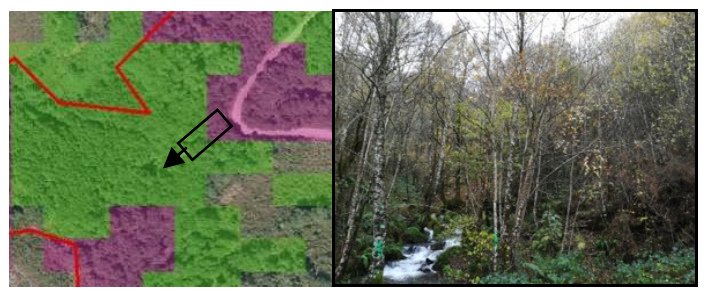

Figure 6. Left: Model 5 classification results overlapped with the MFE. Right: Field work picture. The figure shows an example of forest areas wrongly classified as chestnut forest by the MFE. Red lines represent the MFE polygons. Pink-colored areas are areas classified as chestnut while green-colored areas are classified as others. PNOA Reference image (PNOA, 2016)

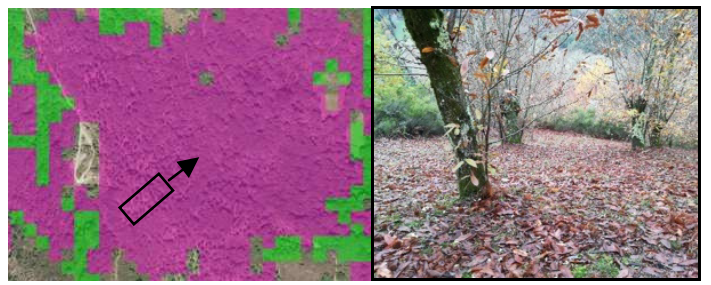

Figure 7. Left: Model 5 classification results overlapped with the MFE. Right: Field work picture. The figure shows an example of chestnut forest areas not included in the MFE chestnut polygons. Pink-colored areas are areas classified as chestnut while green-colored areas are classified as others. PNOA Reference image (PNOA, 2016).

The comparisons performed suggest that the present methodology based on remote sensing techniques can improve the Spanish official cartography. The potential of remote sensing to improve the currently-available information about Spanish forests has been claimed before by (Gómez et al., 2019), therefore the present is a case study which supports this statement. The methodology appears to be replicable in other study areas, however the presence of different tree species could affect the results. 


\section{CONCLUSIONS}

Sentinel 2 multi-temporal analysis through random forest algorithms linked with LiDAR data has been shown to be an efficient tool for performing chestnut forest cartography. The main advantages of the proposed methodology are the use of open-access data and the use of an automatic process. However, in some situations dependence on training areas could be an issue.

The inclusion of months with different phenological stages helps to increase mapping accuracy, as previous studies have indicated. However, the acquisition of data for the wide range of months needed to carry out a complete analysis of the potential of multi-temporal approach for the detection of chestnut plantations was hindered by the presence of shadows due to the topography and climatic conditions of the study area. Further studies should try to record a wide range of months. Additionally, they should focus on links between the results obtained and the different species phenology in order to draw conclusions about which are the most critical phenological stages to include.

On the other hand, chestnut forests in the municipality of Folgoso do Courel were detected and more accurately estimated using new methodologies than by using the official cartography sources, showing that new methods are available that could improve the official cartography. At the same time, a ready-touse product was obtained which can be used as a decisionmaking tool when it comes to chestnut forest management.

\section{ACKNOWLEDGEMENTS}

This project was funded by the Galician Government, Regional Ministry of Rural Areas.

\section{REFERENCES}

Acquadro, A., Torello Marinoni, D., Sartor, C., Dini, F., Macchio, M., Botta, R., 2019. Transcriptome characterization and expression profiling in chestnut cultivars resistant or susceptible to the gall wasp Dryocosmus kuriphilus. Mol. Genet. Genomics 295, 107-120. https://doi.org/10.1007/s00438-019-01607-2

Barrett, F., McRoberts, R.E., Tomppo, E., Cienciala, E., Waser, L.T., 2016. A questionnaire-based review of the operational use of remotely sensed data by national forest inventories. Remote Sens. Environ. https://doi.org/10.1016/j.rse.2015.08.029

Baser, U., Bozoglu, M., 2020. Chestnut blight and technical efficiency in chestnut production: Case study of Aydin Province, Turkey. Sci. Hortic. 263, 109048. https://doi.org/10.1016/j.scienta.2019.109048

Battisti, A., Benvegnù, I., Colombari, F., Haack, R.A., 2014. Invasion by the chestnut gall wasp in Italy causes significant yield loss in Castanea sativa nut production. Agric. For. Entomol. 16, 75-79. https://doi.org/10.1111/afe.12036

Breiman, L., 2001. Random Forest. Mach. Learn. 45, 5-32. https://doi.org/10.1017/CBO9781107415324.004

Conedera, M., Manetti, M., Giudici, F., Amorini, E., 2004. Distribution and economic potential of the Sweet chestnut (Castanea sativa Mill.) in Europe. Ecol. Mediterr. 30, 179-193.
European Space Agency (ESA), 2015. Sentinel-2 user handbook. ESA

Fassnacht, F.E., Latifi, H., Stereńczak, K., Modzelewska, A., Lefsky, M., Waser, L.T., Straub, C., Ghosh, A., 2016. Review of studies on tree species classification from remotely sensed data. Remote Sens. Environ. 186, 64-87. https://doi.org/10.1016/j.rse.2016.08.013

Fernández de Ana-Magán, F.J., Verde Figueiras, M.C., Rodríguez Fernández, A., 1998. O souto un ecosistema en perigo. Xunta de Galicia.

Fernández-López, J., Furones-Pérez, M., Fernández-Cruz, J., Míguez-Soto, B., 2013. Variedades para os soutos novos. Xunta de Galicia.

Gómez, C., Alejandro, P., Hermosilla, T., Montes, F., Pascual, C., Ruiz, L.A., Álvarez-Taboada, F., Tanase, M., Valbuena, R., 2019. Remote sensing for the Spanish forests in the $21 \mathrm{st}$ century: a review of advances, needs, and opportunities. For. Syst. Vol 28, No 1. https://doi.org/10.5424/fs/2019281-14221

Grabska, E., Hostert, P., Pflugmacher, D., Ostapowicz, K., 2019. Forest stand species mapping using the sentinel-2 time series. Remote Sens. 11. https://doi.org/10.3390/rs11101197

Hościło, A., Lewandowska, A., 2019. Mapping forest type and tree species on a regional scale using multi-temporal sentinel-2 data. Remote Sens. 11. https://doi.org/10.3390/rs11080954

IGN (Instituto Geográfico Nacional), Gobierno de España, 2019. http://www.ign.es/web/ign/portal/ide-area-nodo-ide-ign (Accessed on 29/01/2020)

Immitzer, M., Vuolo, F., Atzberger, C., 2016. First experience with Sentinel-2 data for crop and tree species classifications in central Europe Remote Sens. 8. https://doi.org/10.3390/rs8030166

Miteco, 2014. Mapa Forestal de España a escala 1:25.000 (MFE25). https://www.mapa.gob.es/es/desarrollorural/temas/politica-forestal/inventario-cartografia/mapaforestal-espana/mfe_25.aspx. (Accessed on 29/01/2020)

Pereira-Lorenzo, S., Ramos-Cabre, A.M., Díaz-Hernández, B., Ascasíbar-Errasti, J., Sau, F., Ciordia-Ara, M., 2001. Spanish chestnut cultivars. Hort. Sci. 36, 344-347. https://doi.org/10.21273/hortsci.36.2.344

Persson, M., Lindberg, E., Reese, H., 2018a. Tree species classification with multi-temporal Sentinel-2 data. Remote Sens. 10. https://doi.org/10.3390/rs10111794

PNOA, 2016. Plan Nacional de observación del territorio, Gobierno de España. https://pnoa.ign.es/presentacion (Accessed on $31 / 01 / 2020$ )

USC/Xunta de Galicia, 2005. PORN (Proyecto de ordenación de los recursos naturales) Espacio Natural protegido Os Ancares - O courel. Xunta de Galicia

Roces-Díaz, J. V., Díaz-Varela, E.R., Barrio-Anta, M., ÁlvarezÁlvarez, P., 2018. Sweet chestnut agroforestry systems in northwestern Spain: Classification, spatial distribution and an 
ecosystem services assessment. For. Syst. 27, 1-14. https://doi.org/10.5424/fs/2018271-11973

Trapiello, E., Rigling, D., González, A.J., 2017. Occurrence of hypovirus-infected Cryphonectria parasitica isolates in northern Spain: an encouraging situation for biological control of chestnut blight in Asturian forests. Eur. J. Plant Pathol. 149, 503-514. https://doi.org/10.1007/s10658-017-1199-4//

Zlatanov, T., Schleppi, P., Velichkov, I., Hinkov, G., Georgieva, M., Eggertsson, O., Zlatanova, M., Vacik, H., 2013. Structural diversity of abandoned chestnut (Castanea sativa Mill.) dominated forests: Implications for forest management. For. Ecol. Manage. 291, 326-335. https://doi.org/https://doi.org/10.1016/j.foreco.2012.11.015 